\title{
Influencing Factors of Analysts' Property Insurance Demand Based on Grey Relational Analysis
}

\author{
Han Wen Fang Li \\ School of Finance, Guizhou University of Finance and Economics, Guiyang Guizhou \\ 550025 , China
}

\begin{abstract}
For a long time, the total amount of the family property insurance in our country is not large, and the proportion of the property insurance business is also very small. Since 2003, the premium and its proportion in property insurance have been declining year by year. Based on this background, the author thinks that the potential demand of family property insurance into effective demand is the main way to solve the dilemma of property insurance. From the demand perspective, factors that influence the demand for health insurance of farmers mainly include economic, social and cultural factors such as perceived risk, and the representative of the three factor variables in the gray correlation analysis results showed that the structure of consumption expenditure, inflation, risk perception and the family property insurance demand with grey correlation degree strong.
\end{abstract}

\section{Keywords}

Family property insurance demand; Influencing factors; Grey relational analysis

\section{基于灰色关联法的家庭财产保险需求影 响因素分析}

\author{
韩雯 房莉 \\ 贵州财经大学金融学院, 贵阳 550025, 中国
}

摘要：一直以来，我国家庭财产保险的业务总量不大，在迅猛发展的财产保险业务中占比也 很小, 自 2003 年开始, 保费及其在财险中的占比逐年下滑。基于这一背景, 作者认为使得 家庭财产保险的潜在需求转化为有效需求是解决家财险困境的主要途径。本文从需求角度出 发, 认为影响农民健康保险需求的因素主要包括经济、社会文化和风险感知等因素, 并采用 三因素中的代表性变量进行灰色关联分析, 结果显示, 通货膨胀、消费结构支出、风险感知 程度与家庭财产保险需求具有较强的灰色关联度。

关键词：家庭财产保险需求；影响因素；灰色关联分析

1. 引言

新中国保险业务开办之初就有了 家庭财产保险, 是财产保险中的一种 
传统保险业务, 经营历史悠久, 一直 延续至今。家庭财产保险之所以有这 么长的生命力, 是因为它能够为城乡 居民的家庭财产提供多方面的安全保 障, 使社会效益提高。随着我国经济 的发展, 家庭财产在不断增加, 人们 风险意识也在逐步提高, 我国对家庭 财产保险的需求必然逐步增长。然 而, 在我国财产保险迅猛发展的同 时, 家庭财产保险却停滞不前。表 1 中保费占比的数据显示: 家庭财产保险 的业务量在全部财产保险中占比极 低, 并且呈现逐年下降的态势, 2014 年这一数据降至 $0.45 \%$, 家庭财产保险 几乎处于被遗忘的边缘。我国家庭财 产保险的发展困境可以在表 2 中进一 步得到诠释: 这几年间, 我国的财产保 险飞速发展, 年均增长率为 $19 \%$, 机动 车辆保险更是以超过 $20 \%$ 的年均增长率 遥遥领先; 相比之下, 家庭财产保险 出现了发展停滞, 甚至倒退。

表 1

\begin{tabular}{|c|c|c|c|}
\hline \multicolumn{3}{|c|}{$1998^{\sim} 2015$ 年财产保险中家财险保费占比情况 } \\
\hline 年度 & $\begin{array}{c}\text { 财产保险 } \\
\text { 保费( } \\
\text { 家) }\end{array}$ & $\begin{array}{c}\text { 庭财产保费( } \\
\text { 元) }\end{array}$ & $\begin{array}{c}\text { 家庭财产保险保费 } \\
\text { 占财产保险保费比 } \\
\text { 例 } \% \text { ) }\end{array}$ \\
\hline 2006 & 1580 & 11.25 & $0.71 \%$ \\
\hline 2007 & 2086 & 17.01 & $0.82 \%$ \\
\hline 2008 & 2446 & 12.68 & $0.52 \%$ \\
\hline 2009 & 2993 & 15.10 & $0.50 \%$ \\
\hline 2010 & 4027 & 19.30 & $0.48 \%$ \\
\hline 2011 & 4779 & 23.32 & $0.49 \%$ \\
\hline 2012 & 5530 & 28.47 & $0.51 \%$ \\
\hline 2013 & 6481 & 37.87 & $0.58 \%$ \\
\hline 2014 & 7544 & 33.68 & $0.45 \%$ \\
\hline 2015 & 8423 & 41.70 & $0.50 \%$ \\
\hline
\end{tabular}

表 2

\begin{tabular}{|c|c|c|c|c|}
\hline \multicolumn{5}{|c|}{$1998^{2} 2015$ 年财产保险个险种保费收入情况 } \\
\hline 年份 & $\begin{array}{l}\text { 企业财产 } \\
\text { 保险（亿 }\end{array}$ & $\begin{array}{l}\text { 家庭财产 } \\
\text { 保险（亿 }\end{array}$ & \begin{tabular}{|l} 
机动车辆 \\
保险 (亿
\end{tabular} & \begin{tabular}{|l|} 
其他财产 \\
保险（亿
\end{tabular} \\
\hline & 元） & 元） & 元） & 元） \\
\hline 2006 & 157.44 & 11.25 & 1107.87 & 303.44 \\
\hline 2007 & 186.83 & 17.01 & 1484.28 & 397.88 \\
\hline 2008 & 209.63 & 12.68 & 1702.52 & 521.17 \\
\hline
\end{tabular}

续表 2

\begin{tabular}{|c|c|c|c|c|}
\hline 年份 & $\begin{array}{c}\text { 企业财产 } \\
\text { 保险 } \\
\text { 元) }\end{array}$ & $\begin{array}{c}\text { 亿庭财产机动车辆 } \\
\text { 亿其他财产 } \\
\text { 元 }\end{array}$ & $\begin{array}{c}\text { 保险 } \\
\text { 元) }\end{array}$ & $\begin{array}{c}\text { 保险 } \\
\text { 元) }\end{array}$ \\
\hline 2009 & 221.40 & 15.10 & 2155.60 & 600.90 \\
\hline 2010 & 271.60 & 19.30 & 3004.20 & 731.90 \\
\hline 2011 & 329.81 & 23.32 & 3504.17 & 921.70 \\
\hline 2012 & 360.36 & 28.47 & 4005.17 & 1136.00 \\
\hline 2013 & 378.80 & 37.87 & 4720.79 & 1343.54 \\
\hline 2014 & 387.35 & 33.68 & 5515.93 & 1607.04 \\
\hline 2015 & 386.20 & 41.70 & 6199.00 & 1796.10 \\
\hline $\begin{array}{c}\text { 年均复合 } \\
\text { 增长率 }\end{array}$ & $7.52 \%$ & $7.51 \%$ & $19.96 \%$ & $18.50 \%$ \\
\hline & $7.45 \%$ & $-0.31 \%$ & $20.90 \%$ & $22.32 \%$ \\
\hline
\end{tabular}

我国家庭财产保险的潜在需求相 当庞大。首先, 我国人口数额攀升的 同时每户家庭平均人数正在下降，家 庭规模的下降使得家庭对于风险的承 受力降低; 其次, 改革开放以来居民 家庭财产逐年增长，也提高了风险事 故发生时家庭的损失幅度。同时，在 和谐社会的大环境下, 中产阶级在社 会中所占比例逐步提升, 中产阶级的 风险损失机会成本相对较高, 因此相 对而言有着更强烈的避险需求。

那么, 家庭财产保险需求主要受 哪些因素影响呢? 我们认为, 主要有 以下三类：一是经济因素，包括支付 能力和消费支出结构等; 二是社会 文化因素, 主要包括人口年龄结构、 人口受教育程度、保险认知度。三是 风险感知因素。我国家庭有效数据缺 乏等特殊性, 本文将采用灰色关联分 析法对该问题进行分析。

\section{2. 文献综述}

国外在非寿险业务的保险需求的 影响因素方面, 定性分析比较多且年 代较为久远。Szpiro ( 1986 ) Outrevilie (1988) , Skipper （1999）是这方面的代表人物。他们 普遍认为, 理论上消费者的风险厌恶 程度, 教育程度和社会的经济增长程 
度这三个方面是影响非寿险业务保险 需求的重要因素, 并分别进行定性分 析。在家庭财产保险需求的影响因素 方面, Glaeser 和 Sacerdote (1999) 在以上三个因素之外又加入 了保险人的产品定价、产品设计、广 告以及销售渠道这四个因素。但目前 为止现存的文献并没有对这几方面所 能产生的影响做出过定量分析。在财 产保险需求的实证分析方面, Beenstoek, Browne 和 Outervile 的 研究影响颇大。他们在对一个国家的 非寿险需求的影响因素进行实证分析 时普遍采用了横截面数据, 得到的结 论是以人均为代表的经济发展水平和 保险需求显著正相关。而历来被认为 影响很大的保险商品价格反而没有体 现出显著性。

在对我国家庭财产保险影响因素 研究上, 王君 (2012) 认为影响我国 家庭财产需求的影响因素有经济发展 水平、收入水平、保费收入、教育经 费支出、通货膨胀和固定资产投资, 并用多元线性回归模型对需求影响因 素进行实证分析，结果显示居民的收 入水平和上期保费收入对家财险的需 求有正向影响, 经济发展水 (GDP) 有 负向影响，而教育经费支出、通货膨 胀、固定资产投资并没有通过检验。 李思博、樊露阳、张溪钰、贾真 (2012) 通过问卷调查获得数据, 提 取相关因素进行实证分析, 认为家庭 财产保险受主观因素和客观因素影 响。其中, 主观影响因素包括性别、 户口、月收入、购买意愿、了解程度 和购买必要性, 研究结果显示城市居 民中的女性更偏向于购买家财险，消 费者的收入、购买意愿、了解程度和 必要性均与家财险有正向影响关系; 客观因素包括保险的价格、产品的组 合和宣传的途径，结果显示消费者更 易接受价格低、能够自由组合的家财
险, 在宣传途径上更偏向于网络和社 区宣传的方式。

鉴于国内关于家庭财产保险需求 的系统理论论述和实证分析都比较欠 缺, 并且, 目前尚没有文献采用灰色 关联分析法对家庭财产保险需求问题 进行研究, 本文拟做以下工作：一是 对影响家庭财产保险需求的因素进行 理论分析; 二是尝试应用灰色关联分 析法对影响因素与需求之间的关联度 进行排序。

\section{3. 家庭财产保险需求的影响因素}

本研究在变量的选取上, 力求所 选变量能够很好地反映家庭财产保险 的市场结构。根据上述学者的研究, 选取保险费收入作为被解释变量, 衡 量家庭财产保险的需求。解释变量总 共分为三类, 分别为经济影响因素、 社会文化因素、风险感知因素, 具体 说明如下。

\section{1. 经济因素}

（1）经济发展水平。从保险学理 论和保险在世界各国的发展历史来 看, 经济的增长是保险需求总量增加 和保险需求结构升级的重要基础。社 会整体消费结构的变化取决于经济发 展带来的物质水平的提高。

（2）支付能力。支付能力指的是 国民收入水平, 支付能力直接影响农 民的家庭保险保险需求。一般情况 下，经济越发达，国民的收入水平越 高, 则国民支付能力越强。假定其他 条件不变, 他们对家庭财产保险的需 求相应会越多。

（3）消费支出结构。随着收入增 加, 国民基本的衣食需求得到了满 足, 按照马斯洛需求层次理论, 国民 会转向更高层次的需求, 这种需求的 变化可以用恩格尔系数来度量。可以 说, 随着收入增加, 国民的生活水平 
不断提高, 消费结构逐步趋于优化, 这是家庭财产保险的物质契机。

（4）通货膨胀

通货膨胀作为一个环境变量, 主 要从三个方面对保险的需求产生影 响, 第一个方面是价格效应, 是其通 过价格所产生的; 第二方面是收入效 应，是其通过收入水平所产生的；第 三方面是替代效应，是其通过其他环 境变量所产生的, 例如利率水平就是 其中的一种环境变量。通货膨胀水平 的变化会带动消费者对保险产品购买 需求的变化。在本文的实证分析部分 将选取消费者价格指数, 即 CPI 作为 衡量通货膨胀因素的指标。

（5）固定资产投资

社会固定资产投资额的增加会带 动全社会物质财产总量的增加, 进而 使得可能遭受风险损失的家财险投保 标的总量增加, 因为家庭财产保险承 保的标的是家庭拥有的财产及其相关 责任, 由此可见固定资产投资的增加 会增加家财险的需求。

（6）理财替代产品

家庭财产保险是家庭资产配置的 重要方面, 它不仅具有风险保障功 能, 同时具有储蓄、投资等功能。这 就与其他理财产品产生替代竞争, 本 文选取国民储蓄量作为衡量该因素的 指标。

\section{2. 社会文化因素}

\section{（1）人口受教育程度}

人口受教育程度直接影响家庭观 念和投资理念。许多研究表明, 人口 受教育程度越高, 就会越注重培养健 康的生活方式和对健康进行投资。改 革开放以来, 我国国民的受教育程度 呈不断增加趋势。受教育程度的提高 为农民消费健康保险提供了软条件。 随着受教育水平的提高, 人们会更加 关注自己和家人的风险，从而更有意
识通过购买保障产品来分散这种风 险, 为自己和家人提供保障。

(2) 保险认知度

人们对保险产品及其作用的认知 程度的高低均会影响其购买意愿。一 般而言, 当人们意识到保险产品对自 己有用或者对自家财产有担忧时, 其 对家庭财产保险的需求往往会增加, 购买欲望也会随之增强, 从而会增加 保险消费。保险的消费意识强弱综合 反映了对于家庭风险的防范和在家庭 风险中财产损失的判断与评估。保险 密度不仅能够反映商业保险在截面上 的覆盖度, 还可以从量上反映其被认 知程度。故而, 选取保险密度作为衡 量人们对保险认知程度的指标。

(3) 互联网普及程度:

据统计, 2014 年中国网民规模达 6. 49 亿, 互联网普及率达 $47.9 \%$ 。面 对风起云涌的互联网新时代, 不了解 互联网思维将成为时代弃儿。在互联 网时代, 由于信息量大, 信息流动 快, 能最大程度消除信息不对称, 信 息不对称被加速打破后，投保人购买 决策过程发生巨大变化, 投保人在家 中上网就可以获取更多的知情权和选 择权, 买卖双方权力将发生转移, 促 使行业加速进入用户主权时代。

\section{3. 风险感知因素:}

随着经济、科技等不断进步和社 会财富的增加, 人类面临越来越多的 风险威胁和越来越大的风险损失。财 产保险的业务对象是企、事业单位等 团体，消费者的保险意识更多来自于 其对风险的感知, 即财产由于风险而 造成损失的刺激。因此，本文选择可 保风险的损失作为反映保险意识的变 量, 该变量由自然灾害、火灾、海难 和盗窃犯罪受理数量三个数据合成, 这样既可以全面反映财产保险的承保 
风险, 又能够全面反映整个社会可保 风险的损失状况。

\section{4. 模型的选择及分析}

与其他保险产品的需求相比, 家 庭财产保险需求是一个复杂的系统, 受到诸多因素的影响, 要收集完备信 息对其进行分析是个浩大的工程, 我 们无法穷尽代表影响因素的指标，同 时, 有些指标因为缺乏连续的统计数 据而无法被包含在模型中。因此, 本 文只是选取了诸多影响因素中的代表 性指标, 家庭财产保险需求系统中信 息量少, 数据少, 无规律可循, 采用 回归分析局限性较大，本文拟用灰色 系统理论的灰色关联分析法进行家庭 财产保险需求的分析。灰色关联分析 是根据因素之间发展态势的相似或相 异程度来衡量因素之间关程度的方 法。它以 “部分信息已知, 部分信息 未知” 的 “小样本”、“贫信息” 不 确定性系统为研究对象, 通过对 “部 分”已知信息的生成和开发, 提取有 价值的信息, 实现对系统运行规律的 正确认识和有效控制。它的基本思想 是根据序列几何形状的相似程度来判 断因素之间的关系是否紧密。曲线的 几何形状越接近，相应序列之间的关 联度就越大, 反之就越小。由于灰色 关联分析是按照发展趋势进行分析, 对样本量的多少没有要求, 也不需要 典型的分布规律, 只要原始数据列有 四个以上数据就可以。由此可见, 这 一方法比较适合应用于目前我国家庭 财产保险需求系统中信息量少、数据 少、无规律可循的这种情况。在经济 因素中, 本文拟选择的指标为人均 GDP （X1）、国民收入水平（X2）、恩格 尔系数（X3）、消费价格指数 (X4) 、房地产固定资产投资 （X5）、国民人民币储蓄量（X6）。 社会文化因素中选择指标为教育经费
支出（X7）、保险密度（X8）、互联 网普及率（X9）。风险感知因素选择 指标为自然灾害、火灾、海难和盗窃 犯罪受理数量（X10）。选择家财险保 费收入作为被解释变量 $\mathrm{X} 0$ 。本文选取 以上各指标 2000 年 2015 的数据 进行分析。分析数据来自《中国统计 年鉴》、《中国卫生统计年鉴》、

《中国人口统计年鉴》、 《中国人口 和就业统计年鉴》

\section{（1）邓氏关联度}

本文首先按照灰色关联分析的基 本方法分析各因素对家财险保费收入 的影响程度。最终的计算结果为:

$\begin{array}{llllllllll}\gamma 1 & \gamma_{2} & \gamma_{3} & \gamma_{4} & \gamma_{5} & \gamma_{6} & \gamma_{7} & \gamma_{8} & \gamma_{9} & \gamma_{10}\end{array}$ $\begin{array}{lllllllllllllll}0.80 & 0.79 & 0.95 & 0.95 & 0.61 & 0.78 & 0.77 & 0.76 & 0.66 & 0.95\end{array}$ $\begin{array}{llllllllll}45 & 41 & 04 & 34 & 18 & 48 & 77 & 61 & 03 & 03\end{array}$

\section{$\gamma 4>\gamma 3>\gamma 10>\gamma 1>$ $\gamma 2>\gamma 6>\gamma 7>\gamma 8>\gamma 9>$} $\gamma 5$ 。即: 消费价格指数 $>$ 恩格尔系数 $>$ 自然灾害、火灾、海难和盗窃犯罪受 理数量 $>$ 人均 GDP $>$ 国民收入水平 $>$ 国民 人民币储蓄量 $>$ 教育经费支出 $>$ 保险密 度 $>$ 互联网普及率 $>$ 房地产固定资产投 资。

（2）灰色绝对关联度

同样利用程序化的计算方式可得 灰色绝对关联度结果：

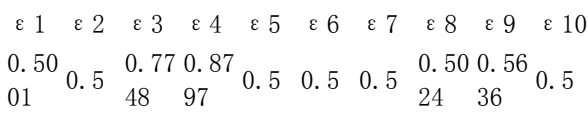

(3) 灰色绝对关联度顺序为: $\varepsilon$ 4> $\varepsilon 3>\varepsilon 9>\varepsilon 8>\varepsilon 1>\varepsilon 2=\varepsilon 5=\varepsilon 6=\varepsilon$ $7=\varepsilon 10$

灰色相对关联度计算结果:

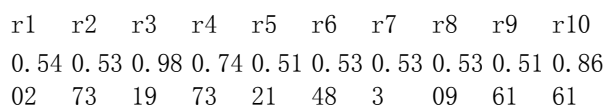

(4) 灰色相对关联度顺序 为: $r 3>r 10>r 4>r 1>r 2>r 6>r 7>r 8>r 9>r 5$ 灰色综合关联度计算结果: 


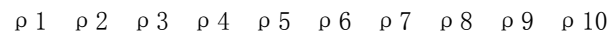
$\begin{array}{lllllllllllllll}0.52 & 0.51 & 0.87 & 0.81 & 0.50 & 0.51 & 0.51 & 0.51 & 0.53 & 0.68\end{array}$ $\begin{array}{llllllllll}01 & 86 & 84 & 35 & 6 & 74 & 65 & 67 & 98 & 31\end{array}$

灰色综合关联度顺序为： $\rho 3>\rho$ $4>\rho 10>\rho 9>\rho 1>\rho 2>\rho 6>\rho 8>\rho 7 \rho$ 5

（5）灰色关联分析小结

以上灰色关联分析结果显示, 对 家庭财产保费收入影响较大的因素是 经济因素（通货膨胀及消费支出结 构）和风险感知因素。

\section{5. 结论及建议}

由上述所选的十种因素与家财险 关联度的大小可以发现, 通货膨胀对 家财险险需求的影响最大, 其余依次 为消费支出结构、风险感知程度。固 定资产投资对家财险需求的影响最 小, 但是二者的关联度仍然达到了 0.5 以上, 依然能对健康险的需求做出 一定的解释。通过上述分析, 可得研 究结果如下: 第一, 居民消费价格指 数灰色关联度最大, 说明该指标所代 表的通货膨胀因素对家财险需求影响 最显著。通货膨胀率越高, 消费者的 实际收入水平就越低, 因此从保费收 入总量上也会相应减少。第二, 随着 收入增加, 国民基本的衣食需求得到 了满足, 按照马斯洛需求层次理论, 国民会转向更高层次的需求, 这种需 求的变化可以用恩格尔系数来度量。 可以说, 随着收入增加, 国民的生活 水平不断提高, 消费结构逐步趋于优 化, 这是家庭财产保险的物质契机。 第三，人们在遭遇过风险之后，会大 大增加对风险的厌恶程度, 从而选择 保险来保障其家庭。

以上三种因素，通货膨胀是国家 宏观经济因素，国民消费结构与风险 感知是国民的心理因素。国家层次: 影响通货膨胀因素有固定资产投资、 GDP、货币发行量、外汇储备等等, 如
要刺激家财险需求, 需要将视线转向 国家, 从国家宏观角度出发, 宏观调 控经济。实施适度从紧的货币政策和 人民币货币政策; 逐渐有序放宽对成 品油、电价在内价格管制制度, 让其 随市场波动, 与国际市场价格体系接 轨; 改善我国能源结构和高能耗产 业。个人层次: 当人们的可支配收入 增加, 满足基本需求之后, 消费结构 多样化, 当然就会考虑家庭安全问 题。加大农业投入，提高农民收入; 增加就业岗位, 缓解失业压力; 提高 农村扶贫标准; 扩大社会保障范围, 提高社会保障标准。保险公司: 人们 在遭遇风险之后会大大增加风险厌恶 感，如何将这种风险厌恶提到最大化 是保险公司应该考虑的问题，同时需 要注意的是不能够夸大其辞, 恶意造 谣, 这将会使原本就处于低谷期保险 形象再次大跌。

\section{参考文献}

[1] Sipiro,Outreville.Relative risk aversion around the world $[\mathrm{J}]$.Studies in Banking and Finance, 1988(6): 123-129.

[2] Szpiro. Measuring risk aversion: an altemativ aprroach[J]. The Review of Economes and Statisties, 2009(68): 156-159. (4) : 31-33.

[3] Beenstoek M,Dickinson G,Khajuria S.The relationship between property-liablity insurance premiums and income.An international analysis[J].Journal of Risk and Insurance,1988,55(2):259-262.

[4]王珺. 我国家庭财产保险问题研究 [D]. 东北农业大学硕士学位论文, 2012 (6) : 2-3, 9-10.

[5]张溪钰, 訤露阳, 李思博, 等. 我 国家庭财产保险影响因素分析及发 展建 议 $[\mathrm{J}]$. 江苏商论, 2012 (17) : 151-151. 